\title{
Integrated effect of EGFR and PAR-1 signaling crosstalk on airway hyperresponsiveness
}

\author{
TAKAHIRO YOSHIKAWA $^{1}$ and HIROSHI KANAZAWA ${ }^{2}$ \\ Departments of ${ }^{1}$ Sports Medicine and ${ }^{2}$ Respiratory Medicine, Osaka City University \\ Graduate School of Medicine, Abeno-ku, Osaka 545-8585, Japan \\ Received January 26, 2012; Accepted March 30, 2012
}

DOI: $10.3892 / \mathrm{ijmm} .2012 .981$

\begin{abstract}
Among previous genetic studies for asthma, inconsistent findings were often reported. We used a new approach to examine an integrated effect of haplotype blocks, newly termed 'haplotype cluster' over two different types of receptors which share common intracellular pathways on airway hyperresponsiveness (AHR). We recruited 165 young atopic adults without respiratory symptoms and measured airway responsiveness to methacholine and classified them into two groups, those with AHR $\left(\mathrm{PC}_{20}<8.0 \mathrm{mg} / \mathrm{ml}\right)$ and without AHR. In addition, we identified haplotype blocks or cluster tagging single nucleotide polymorphisms (SNPs) through two genes, epidermal growth factor receptor (EGFR) and protease activated receptor (PAR)-1, in all subjects, and compared the frequencies of haplotype block or cluster between subject groups. Significant differences in the frequencies were observed in the haplotype blocks within the EGFR gene (rs4947972, rs12718945 and rs2072454; rs4947972, rs12718945 and rs2227983; and rs4947972, rs12718945 and rs2293347) and the PAR-1 gene (rs37243 and rs253072). An integrated effect was also observed in one haplotype cluster consisting of both regions of the EGFR gene (rs2293347) and the PAR-1 gene (rs253072) $(\mathrm{P}=0.0426)$. Our results suggest the possibility that the integrated effect of functionally-related EGFR and PAR-1 genes (haplotype cluster) is associated with susceptibility to AHR.
\end{abstract}

\section{Introduction}

Bronchial asthma is a chronic lung inflammatory disease that affects increasing numbers of people worldwide. Based on evidence of familial concordance of asthma (1), considerable efforts have been put into the search for genes predisposing to

Correspondence to: Dr Takahiro Yoshikawa, Department of Sports Medicine, Osaka City University Graduate School of Medicine, 1-4-3 Asahi-machi, Abeno-ku, Osaka 545-8585, Japan E-mail: tkhr6719@med.osaka-cu.ac.jp

Key words: genetic polymorphism in asthma, haplotype cluster, airway hyperresponsiveness, epidermal growth factor receptor, protease activated receptor-1, signaling crosstalk asthma over the last few decades. Various genetic studies have so far identified more than 40 candidate genes (2) by candidate gene approach [tumor necrosis factor (TNF)- $\alpha$, interleukin (IL)-4, glutathione S-transferase $\pi 1$ (GSTP1)], by positional cloning or positional candidate gene approach [disintegrin and metalloproteinase (ADAM)-33, Fc fragment of high affinity immunoglobulin-E receptor-1 $\beta$ subunit (FCERIB)], and by Genome Wide Association Studies (GWAS) (ORMDL3) (3-10). However, these analyses were often hampered by inconsistent results among studies. In most investigations, the asthma phenotype was considered to be present if it had been diagnosed by a physician. Because there are no common and absolute standard of asthma diagnosis, the diagnosis tends to be up to physicians who make their own clinical judgment. In addition, the characteristics of study subjects are likely to vary among studies because of diverse clinical features of asthma. It is thus important to select a simple and absolute phenotype alone for accurate analysis. In this regards, airway hyperresponsiveness (AHR) is one of the most important phenotypes that asthmatic patients exhibit in common. AHR is defined as an increase in sensitivity to a wide variety of inhaled agents such as methacholine and histamine which induce bronchoconstriction. Measurements of AHR are more objective than clinical judgments by individual physicians. Indeed, protocadherin 1 gene (PCDH1) was recently identified as one of the susceptibility genes for AHR in adults and in children diagnosed with asthma (11).

The analysis of single nucleotide polymorphism (SNP) and haplotype has provided evidence that multiple molecules are involved in the pathophysiology of phenotypic traits of interest. However, it should be noted that many of these biological molecules are unlikely to produce only a simple additive effect on the development of the asthma phenotype but they appear to be mutually interrelated and to generate synergistic or antagonistic effects through crosstalk network mechanisms. Accordingly, it is more beneficial to examine such coordinated effects of multiple genetic factors. Previous studies have demonstrated that the expression of epidermal growth factor receptor (EGFR) is up-regulated in the damaged epithelium of the asthmatic airways (12). Furthermore, we previously reported the possible association of EGFR polymorphisms with asymptomatic AHR in young atopic adults (13). The protease activated receptor family (PAR-1, -2, -3 and -4) has also received attention in studies of allergic diseases, and 
particularly PAR-1 has been shown to induce diverse biological functions, such as tissue remodeling, mediated by thrombin in numerous cells and tissues in airways (14). Previous studies have shown that the signal pathways of PAR-1 can share those of EGFR through intracellular crosstalk (referred to as PAR-1induced EGFR transactivation) (15). Thus, combined genetic analysis of these two separate molecules may shed light on the pathophysiology of AHR. Daly and coworkers (16) suggested that a genomic region could be largely divided into discrete portions with several markers of SNPs (haplotype blocks). A haplotype block contains several common SNPs, and each block has limited patterns of SNP sequences, which appear to arise from common historical recombination events. However, beyond a single haplotype block with historical and material linkage on a single chromosome, it might be useful to perform a multiple-gene investigation to determine integrated effects of functionally-related genes, newly termed 'haplotype clusters', over a large range of genomic regions and chromosomes.

Our hypothesis was that polymorphisms in the gene region of PAR-1 (chromosome 5q13) and EGFR (chromosome 7p12) affect the expression of these molecules and also modify PAR-1-induced EGFR transactivation, resulting in individual differences in the epithelial repair processes which contribute to increased airway response to methacholine provocation. To test this hypothesis, we performed combined analysis of polymorphisms of these two separate genes independent of previous studies (13), by examining the difference in the frequencies of a haplotype cluster as well as haplotype block on these gene regions between cases (young asymptomatic adults with AHR) and controls (those without AHR). The purpose and rationale for the design of the present study is quite different from those in large-scaled studies.

\section{Materials and methods}

Participants. Participants were recruited randomly from a list of university students, and only individuals who had never smoked were asked to participate in the study. All of the participants were asked to complete questionnaires that examined their past and current experience of the following events: respiratory symptoms including wheezing episodes, diagnosed asthma, other respiratory illness, allergic diseases and medication use. All participants underwent physical examinations and blood sampling. First, only individuals without respiratory symptoms who met at least one of the following criteria were included in the present study as study subjects: i) current or past history of allergic diseases, such as hay fever and atopic dermatitis, that had been diagnosed by specialists; ii) total serum IgE levels of $>250 \mathrm{IU} / \mathrm{ml}$; or iii) one or more specific IgE levels of $>0.34 \mathrm{UA} / \mathrm{ml}$ to common aeroallergens, including house dust mites, animal dander, and cedar pollen, as determined by a radioallergosorbent test (RAST) using UniCAP IgE fluoroenzyme immunoassays (Sweden Diagnostics, Uppsala, Sweden).

A spirometer (Chestac-25F; Chest Co., Tokyo, Japan) was used to obtain all spirometric measurements. The methacholine provocation test with conventional pulmonary measures was performed as recommended by American Thoracic Society (ATS) guidelines (17). Subjects who had used any medication, or had a respiratory infection or a transient exacerbation of any allergic disease within 4 weeks prior to the methacholine provocation, were excluded to avoid confounding effects. Subjects were challenged with normal saline diluent and then with a range of available concentrations of methacholine (0.3 to $16.0 \mathrm{mg} / \mathrm{ml}$ ) from DeVilbiss 646 nebulizer (DeVilbiss Co., Somerset, PA, USA). The airway responsiveness of each participant was expressed as the concentration of methacholine causing a $20 \%$ fall in forced expiratory volume in $1 \mathrm{sec}$ $\left(\mathrm{FEV}_{1}\right)$ from the baseline $\mathrm{FEV}_{1}\left(\mathrm{PC}_{20}\right)$. If the $\mathrm{PC}_{20}<8.0 \mathrm{mg} /$ $\mathrm{ml}$, the subject was categorised as having AHR. Statistical analyses of subject background data were performed using SPSS ver. 18 for Windows (SPSS Inc., Chicago, IL). The background data are expressed as medians (25th and 75th percentiles). However, the spirometric data, which were normally distributed, are presented as mean \pm SD. Serum total IgE levels were transferred to a logarithmic function to yield normally skewed data during the analyses. The age, blood eosinophils and serum specific IgE levels of the subject groups were compared using the Mann-Whitney U test between subjects with AHR and those without AHR. The spirometric data and the $\log$ values of serum total $\operatorname{IgE}$ were compared using as unpaired t-test between the two subject groups. The categorical data were compared between subject groups using $\chi^{2}$ tests. P-values $<0.05$ were indicated statistically significant.

All volunteers were recruited into our study under informed written consent, and performance of the study was approved by the Ethics Committee of Osaka City University Medical School, Japan. All procedures were performed according to the research ethics of the Declaration of Helsinki (18).

Analysis of polymorphism in the EGFR and PAR-1 genes. We selected twelve SNPs in the EGFR gene and seven SNPs in the PAR-1 gene (Table I) from the SNP data list available from the website of the National Center for Biotechnology Information (NCBI). These lists can be accessed by entering the keywords for 'EGFR' or 'F2R (an official symbol for PAR-1)' in the dbSNP Database of the NCBI website, in which a corresponding 'rs' number is assigned to each SNP locus. The criteria for selection of the SNP loci were as follows: loci at even intervals between neighboring SNPs (whole gene length of EGFR and PAR-1; about 200,000 and 20,000 bases, respectively) irrespective of the region (intron or exon) and function (synonymous or missense) in order to use these SNPs simply as markers on the gene map and to identify gene region(s) (haplotype block or cluster) involved in the difference in the phenotype between the two subject groups. Next, we obtained DNA sequence data around the SNP locus of interest from each SNP database. Then, each fragment of two gene regions was polymerase chain reaction (PCR)-amplified by cycle sequencing analysis as described below. In the present study, numbering, e.g. +456 , was relative to the transcription start codon.

Genomic DNA was extracted from leukocytes by Genomic, a kit for DNA extraction from blood (Talent MD, Trieste, Italy). The regions of the primer pairs used for the sequencing of the EGFR and PAR-1 regions of interest in the present study are listed in Table I. The PCR reactions were run on PTC-225 DNA Engine Tetrad Thermal Cyclers (BioRad, Hercules, CA), using HotStarTaq polymerase (Qiagen $\mathrm{GmbH}$, Hilden, Germany). PCR products were purified using ExoSAP-IT (USB Corp., Cleveland, OH). Subsequently, 
sequencing was performed on PTC-225 DNA Engine Tetrad Thermal Cyclers (Bio-Rad), using the BigDye Terminator v3.1 Cycle Sequencing kit (Applied Biosystems, Foster City, CA) according to the manufacturer's instructions. After removal of excess dye terminators by ethanol precipitation, the product interrogation was performed using the ABI 3730xl DNA analyzer (Applied Biosystems). The products were analyzed with the aid of the Sequencher 4.2 software (Gene Codes Corporation, Ann Arbor, MI).

Inferring phase relationships and haplotype blocks. It is impossible to interpret individual multilocus genotypes (haplotypes) solely by the DNA sequence data above because gametic phase of multiple-site heterozygous diploids cannot be determined. Expectation-maximization (EM) algorithm (19) has been suggested to be adapted for the problem of inferring phase relationships in haplotypes (20). One of the groups described the EM algorithm as it applied to the problem of inferring haplotype frequencies under that assumption of a Hardy-Weinberg equilibrium (21). The converged value of the EM algorithm based upon the maximum likelihood depends on initial values except when there is no local maximum. 'Haplotype blocks' are selected as blocks of strong LD (linkage disequilibrium) which are stable among various initial values $(22,23)$. After defining haplotype blocks, we estimated haplotype frequencies. These blocks can be thought of as a unit of inheritance.

The diplotype/diplotype frequency for each subject was estimated using the following likelihood function, $L(\Theta)(23)$ :

$$
\begin{gathered}
L(\Theta)=P\left(g_{1}, g_{2}, \cdots g_{k}, \cdots g_{189} \mid \Theta\right)=\prod_{k=1}^{165} P\left(g_{k} \mid \Theta\right), \\
\Theta=\left(\theta_{1}, \theta_{2} \cdots \theta_{i} \cdots \theta_{j} \cdots \theta_{2^{n}}\right)
\end{gathered}
$$

where $\mathrm{n}$ is the number of polymorphic loci of interest on the EGFR and PAR-1 gene ( $n=1$ to 19$)$, and all number of possible haplotypes is $2^{n}$. $\theta_{i}$ is the frequency of the $i$ th haplotype, and $\Theta$ is the vector of all haplotype frequencies. $g_{k}$ is a sequence of SNP data set consisting of observed (paired, unphased) alleles on $n$ loci for the $k$ th subject in all 165 subjects. $P\left(g_{k} \mid \Theta\right)$ is the probability of diplotype corresponding to the unphased data $g_{k}$. Thus,

$$
\begin{aligned}
& P\left(g_{k} \mid \Theta\right)=\sum_{(i, j) \in Q k} \theta i \theta j, \\
& L(\Theta)=\prod_{k=1}^{165} P\left(g_{k} \mid \Theta\right)=\prod_{k=1}^{165} \sum_{(i, j) \in Q k} \theta i \theta j
\end{aligned}
$$

$Q_{k}$ is a set of all possible pair permutation $(i, j)$ consisting of two haplotype elements in the data set $g_{k}$.

$$
\begin{aligned}
& \hat{\Theta} \equiv \arg \max _{\Theta} L(\Theta), \\
& \hat{d}_{k} \equiv \arg \max _{\{d k\}} P\left(d_{k} \mid \Theta\right)
\end{aligned}
$$

$\hat{\Theta}$ is maximal likelihood estimate of $\Theta$. $\hat{d}_{k}$ denotes the most probable diplotype for the $k$ th subject. In other words, $\hat{\Theta}$ is the converged value for $\Theta$ (initial value) and $\hat{d}_{k}$ is the converged value for $d_{k}$ (initial value), respectively.

Significance test for independence. To identify genetic markers at the region of interest, including single alleles (SNPs) or the combination of these markers (haplotype) within haplotype blocks, which is more or less frequent among individuals with AHR (cases) than among those without AHR (controls), a case-control analysis was performed with a 2 (cases and controls) $\mathrm{x} k$ ( $k$, the number of haplotypes within a block for cases and controls) contingency table. After estimating haplotype frequencies in blocks, we performed case-control analysis for haplotype frequencies within a block. Here, the null hypothesis to be tested is that haplotype frequencies for cases and controls in the haplotype block are equal. Thus, this is one significant test for each haplotype block (hypothesis), and does not require multiple comparison correction like Bonferroni. But, this contingency table may have $<5$ in a cell because some haplotypes are not so common for all samples. We calculated the P-value directly using the Fisher's exact test. The haplotype blocks in which significance levels $<5 \%$ (twotailed) were selected.

The Pearson $\chi^{2}$ statistic value can also be estimated by

$$
\chi^{2}=2 n \sum_{l=1}^{l=k} \frac{\left(\mathrm{P}_{1 l}-\mathrm{P}_{2 l}\right)^{2}}{\mathrm{P}_{1 l}+\mathrm{P}_{2 l}}, \quad n=n_{1}+n_{2}
$$

where the $n_{1}$ and $n_{2}$ are the sample sizes of cases and controls, respectively. $\mathrm{P}_{l l}$ and $\mathrm{P}_{2 l}$ are the observed frequencies of the $l$ th haplotype in the cases and controls, respectively.

In addition to the estimation of P-values and Pearson's $\chi^{2}$ statistic values for each block, we calculated P-values as a casecontrol analysis with a 2 (cases and controls) x 2 (e.g. C-T-A vs. non-C-T-A) contingency table in each haplotype within a haplotype block to infer whether the haplotype or haplotypes (e.g. C-T-A) cause the significance in the block. We calculated the $\mathrm{P}$-value for each haplotype by the Fisher's exact test. In addition, we also calculated the odds ratio (OR) and risk ratio (RR) with those of $95 \%$ confidence interval (CI). If the lower limit was higher than 1.0, it was taken to devote significant differences. Although the case-control test was performed, it is reasonable to show the RR as well as the OR. While OR tends to be weighted when the frequency of interest is close to 0.0 and 1.0, RR has a trend to be weighted when the frequency of interest is lower.

Inferring haplotype cluster between two haplotype blocks. Furthermore, in the exact similar manner as described above, we calculated the P-value, Pearson's $\chi^{2}$ statistical value for the integrated two haplotype blocks (haplotype cluster) and then, also estimated the $\mathrm{P}$-values as a case-control analysis with a 2 (cases and controls) x 2 (e.g. C-T-A vs. non-C-T-A) contingency table in each haplotype within a haplotype cluster.

If the haplotype blocks are defined well, $\hat{d}_{k}$ (the most probable diplotype frequency for $k$ th subject) is expected to be 1.00. In this condition, the maximum likelihood estimation of the diplotype combination (haplotype cluster) becomes simple. In other words, when the diplotype of the $k$ th subject on haplotype block 1 and 2 are $\mathrm{d} 1=\mathrm{h} 1 / \mathrm{h} 2$ and $\mathrm{d} 2=\mathrm{h} 3 / \mathrm{h} 4$ respectively, the possible haplotype clusters and diplotype cluster are either $\mathrm{dc} 1=\mathrm{h} 1 \mathrm{~h} 3 / \mathrm{h} 2 \mathrm{~h} 4$ or $\mathrm{dc} 2=\mathrm{h} 1 \mathrm{~h} 4 / \mathrm{h} 2 \mathrm{~h} 3$. Then we can estimate the haplotype cluster/diplotype cluster of each subject.

The diplotype/diplotype frequency for each subject are estimated using following likelihood function, $L(\Theta)(23)$ in the same way as described above but more simply:

$$
\begin{gathered}
L(\Theta)=P\left(g_{1}, g_{2}, \cdots g_{k}, \cdots g_{189} \mid \Theta\right)=\prod_{k=1}^{165} P\left(g_{k} \mid \Theta\right), \\
\Theta=\left(\theta_{1}, \theta_{2} \cdots \theta_{i} \cdots \theta_{j} \cdots \theta_{2^{n}}\right)
\end{gathered}
$$


Table I. Frequencies of each SNP in the EGFR and PAR-1 genes.

\begin{tabular}{|c|c|c|c|c|c|}
\hline SNP locus & Region & SNP locus & PCR primer & Allele frequencies (\%) & Protein residue \\
\hline \multicolumn{6}{|l|}{ EGFR } \\
\hline rs 12668421 & Intron 1 & +22207 & +21716 to +22407 & $\mathrm{~A}(14.5) \mathrm{T}(85.5)$ & - \\
\hline rs4947488 & Intron 1 & +29585 & +29220 to +29785 & $\mathrm{~T}(14.0) \mathrm{A}(86.0)$ & - \\
\hline rs 11766798 & Intron 1 & +37349 & +37149 to +37849 & G (10.9) A (89.1) & - \\
\hline rs 723527 & Intron 1 & +47902 & +46520 to +48681 & $\mathrm{G}(98.8) \mathrm{A}(1.2)$ & - \\
\hline rs9642564 & Intron 1 & +58364 & +58164 to +58564 & $\mathrm{~A}(89.7) \mathrm{G}(10.3)$ & - \\
\hline rs4947972 & Intron 1 & +74073 & +73873 to +74273 & C (89.1) G (10.9) & - \\
\hline rs 12718945 & Intron 1 & +105993 & +105640 to +106193 & $\mathrm{G}(70.0) \mathrm{T}(30.0)$ & - \\
\hline rs 13247687 & Intron 1 & +114806 & +114606 to +115006 & $\mathrm{~A}(75.2) \mathrm{G}(24.8)$ & - \\
\hline rs2072454 & Exon 4 & +127378 & +127178 to +127578 & $\mathrm{~T}(27.6) \mathrm{C}(72.4)$ & Asn/Asn \\
\hline rs 2227983 & Exon 13 & +142285 & +142085 to +142485 & G (35.5) A (64.5) & Lys/Arg \\
\hline rs 1050171 & Exon 20 & +162093 & +161893 to +162293 & G (76.7) A (23.3) & Gln/Gln \\
\hline rs2293347 & Exon 25 & +181946 & +181746 to +182146 & A (40.6) G (59.4) & Asp/Asp \\
\hline \multicolumn{6}{|l|}{ PAR-1 } \\
\hline rs27135 & Intron 1 & +711 & +456 to +966 & $\mathrm{G}(28.2) \mathrm{A}(71.8)$ & - \\
\hline rs 2227750 & Intron 1 & +1332 & +1077 to +1587 & $\mathrm{G}(98.0) \mathrm{C}(2.0)$ & - \\
\hline rs 37243 & Intron 1 & +2187 & +1639 to +2387 & G (22.1) A (77.9) & - \\
\hline rs37244 & Intron 1 & +2979 & +2480 to +3544 & $\mathrm{~T}(77.9) \mathrm{G}(22.1)$ & - \\
\hline rs 253072 & Intron 1 & +12687 & +11177 to +14835 & $\mathrm{~A}(48.2) \mathrm{G}(51.8)$ & - \\
\hline rs 153311 & Intron 1 & +15691 & +14929 to +15890 & $\mathrm{C}(77.9) \mathrm{A}(22.1)$ & - \\
\hline rs5893 & Exon 2 & +16414 & +16314 to +16514 & $\mathrm{~A}(99.7) \mathrm{G}(0.3)$ & Ser/Gly \\
\hline
\end{tabular}

where $n$ is the number of haplotypes in one haplotype block of interest on the EGFR gene $\mathrm{x}$ the number of haplotypes in another haplotype block of interest on the PAR-1 gene, and all number of possible haplotypes in a block is known in the above calculation. $\theta_{i}$ is the frequency of the $i$ th haplotype cluster, and $\Theta$ is the vector of all haplotype cluster frequencies. $g_{k}$ is a sequence of diplotype cluster consisting of estimated (paired) haplotype clusters on $n$ haplotype block for the $k$ th subject in all 165 subjects. $\mathrm{P}\left(g_{k} \mid \Theta\right)$ is the probability of diplotype cluster corresponding to the data $g_{k}$. Thus,

$$
\begin{aligned}
& P\left(g_{k} \mid \Theta\right)=\sum_{(i, j) \in Q k} \theta i \theta j, \\
& L(\Theta)=\prod_{k=1}^{165} P\left(g_{k} \mid \Theta\right)=\prod_{k=1}^{165} \sum_{(i, j) \in Q k} \theta i \theta j
\end{aligned}
$$

$Q_{k}$ is a set of all possible pair permutation $(i, j)$ consisting of two haplotype cluster elements in the data set $g_{k}$.

$$
\begin{aligned}
& \hat{\Theta} \equiv \arg \max _{\Theta} L(\Theta), \\
& \hat{d}_{k} \equiv \arg \max _{\{d k\}} P\left(d_{k} \mid \Theta\right)
\end{aligned}
$$

$\hat{\Theta}$ is maximal likelihood estimate of $\Theta . \hat{d}_{k}$ denotes the most probable diplotype cluster for the $k$ th subject. In other words, $\hat{\Theta}$ is the converged value for $\Theta$ (initial value) and $\hat{d}_{k}$ is the converged value for $d_{k}$ (initial value), respectively.

\section{Results}

Young adult Japanese subjects $(n=165 ; 54$ males, 111 females; aged 18 to 20 years) participated in the study. Table II presents the background information on the subjects. Methacholine challenge tests were performed for all 165 subjects recruited in the present study. Of 165,54 subjects were categorized as having increased airway response $\left(\mathrm{PC}_{20}<8.0 \mathrm{mg} / \mathrm{ml}\right)$ and 111 subjects as having normal airway response $\left(\mathrm{PC}_{20} \geq 8.0 \mathrm{mg} / \mathrm{ml}\right)$. No significant differences were observed between these two subject groups in age, gender, prevalence of allergic rhinitis. High blood eosinophil counts and serum IgE levels were observed in samples from subjects with AHR in comparison to those without AHR (eosinophils; $\mathrm{P}=0.033$, serum IgE; $\mathrm{P}=0.012$ ). Serum specific IgE levels did not differ significantly between samples obtained from subjects with and without AHR (data not shown). The mean baseline $\mathrm{FEV}_{1}$ (\% predicted) values were lower in subjects with AHR compared with those without AHR $(\mathrm{P}=0.009)$.

Table I summarizes the allele frequencies of the investigated EGFR and PAR-1 gene loci in our study population. Based on the results, we performed a case-control study. No difference was observed in the prevalence of any single SNP between subjects with and without AHR.

Significant results were observed in the following haplotype block within each gene region: i) rs4947972, rs12718945 and rs2072454 (block-1 in the EGFR gene), ii) rs4947972, rs12718945 and rs2227983 (block-2 in the EGFR gene), iii) rs4947972, rs12718945 and rs2293347 (block-3 in the EGFR gene), or iv) rs37243 and rs253072 (block-4 in the PAR-1 gene). (The Pearson's $\chi^{2}$ value and the corresponding P-value were 13.6 and 0.0183 (block-1), 16.8 and 0.00484 (block-2), 13.1 and 0.0226 (block-3), and 11.9 and 0.00781 (block-4), respectively) (Table III). In each haplotype block, a higher 
Table II. Subject characteristics.

\begin{tabular}{lccc}
\hline & \multicolumn{3}{c}{ Subjects } \\
\cline { 2 - 3 } & Without AHR $(\mathrm{n}=111)$ & With AHR (n=54) \\
\hline Age (years) & $19(19-20)$ & $19(18-20)$ & 0.260 \\
Gender (M/F) & $38 / 73$ & $16 / 38$ & 0.554 \\
Allergic rhinitis, $\mathrm{n}(\%)$ & $60(54.1 \%)$ & $35(64.8 \%)$ & 0.189 \\
Blood eosinophils $\left(/ \mathrm{mm}^{3}\right)$ & $129.7(71.6-199.4)$ & $155.0(98.0-267.3)$ & 0.033 \\
Serum $\log _{10}$ IgE (total) $(\mathrm{IU} / \mathrm{ml})$ & $2.2 \pm 0.6$ & $8.5 \pm 0.7$ & 0.012 \\
FEV1 $(\%$ predicted) & $92.0 \pm 11.8$ & $4.5(2.7-6.0)$ & 0.009 \\
Methacholine $\mathrm{PC}_{20}(\mathrm{mg} / \mathrm{ml})$ & - & - \\
\hline
\end{tabular}

All subjects ( $\mathrm{n}=165)$ were life-long non-smokers and had no current respiratory symptoms. All of them donated blood for SNP studies. During methacholine testing, subjects inhaled saline (baseline) or methacholine solution $(0.3-16 \mathrm{mg} / \mathrm{ml})$ for 2 min by tidal breathing. $\mathrm{PC}_{20}$, the concentration of methacholine causing $\mathrm{FEV}_{1}$ to drop by $20 \%$. Airway hyperresponsiveness (AHR) was defined as $\mathrm{PC}_{20}<8.0 \mathrm{mg} / \mathrm{ml}$. Age, blood eosinophils, and methacholine $\mathrm{PC}_{20}$ was not normally distributed and is presented as median ( 25 and 75 percentile). The data were compared between the two subject groups by Mann-Whitney $\mathrm{U}$ test. $\log _{10} \mathrm{IgE}$ and $\mathrm{FEV}_{1}$ (\% predicted) were normally distributed and are presented as mean $\pm \mathrm{SD}$, and these data were compared between the two subject groups by the unpaired t-test. Categorical data for two subject groups were compared by $\chi^{2}$ test.

frequency of a haplotype, C-T-C (block-1), C-T-A (block-2), C-T-A (block-3), or G-G (block-4) was observed in subjects with AHR than in those without AHR. The OR, 95\% CI and the corresponding P-values were 3.88, 1.89-7.98 and 0.000983 for block-1; 4.11, 1.98-8.54 and 0.000397 for block-2; 5.81, 2.29-14.7 and 0.000869 for block-3; or 13.0, 1.54-109.4 and 0.00619 for block-4, respectively (Table IV).

Of note, an integrated effect was also observed in one haplotype cluster which consists of SNP loci in both EGFR (rs2293347) and PAR-1 (rs253072) gene regions (cluster-1; Pearson's $\chi^{2}$ statistic value $=8.17, \mathrm{P}=0.0426$ ) (Table III) and higher frequency of a haplotype A-A was observed in subjects with AHR than in those without AHR (OR, 2.42; 95\% CI, 1.21-4.83; $\mathrm{P}=0.0216$ ) (Table IV). Our study had adequate statistical power to detect the association of the haplotype with the phenotype of interest.

\section{Discussion}

The present study showed evidence that parallel gene variation (haplotype cluster) of EGFR and PAR-1 is related to the presence or absence of AHR in young adults with atopy. This is the first genetic study focusing on PAR-1 as well as EGFR as a new candidate molecule for the development of AHR, and one of the possible determinants of development of AHR is the complex gene variation in EGFR and PAR-1, newly termed 'haplotype cluster'.

AHR is one of the objective and absolute phenotypes commonly observed in all asthmatic patients (24). The causal relationship between an individual gene (molecule) and the phenotype (AHR) may be unclear because of its complex pathological processes in advanced patients with asthma, such as airway inflammation and structural remodeling. Besides the symptomatic patients, prospective studies revealed that some of the asymptomatic young adults also exhibit AHR (25) and it is thought to be a possible risk factor for future onset of asthma $(26,27)$. In addition, associated factors such as atopy may partly contribute to the relationship (28). Unlike its symp- tomatic counterpart, only minimal changes in airway structure have been observed in the atopic subjects with asymptomatic AHR $(29,30)$. In the present study, we selected a uniform study phenotype among individual subjects to minimize the interplay among multiple pathological components as seen in patients with symptomatic asthma. Thus, we focused on the simple and absolute phenotype of AHR in asymptomatic allergic young adults.

EGFR is a member of the ErbB family of receptor tyrosine kinase (RTK). EGFR activation promotes epithelial repair (31) in damaged airways, and the increased expression contributes to repair of damaged epithelium in asthmatic airways (12). In line with this, it seems plausible that, similar to symptomatic asthma, EGFR activation may play a role in the onset and progression of AHR in the airways of the asymptomatic adults with atopy. Indeed, we previously reported the possible association of EGFR polymorphisms with asymptomatic AHR in young atopic adults (13), and a similar association of haplotype block-1 (rs4947972, rs12718945 and rs2072454), block-2 (rs4947972, rs12718945 and rs2227983) and block-3 (rs4947972, rs12718945 and rs2293347) on the EGFR gene with the phenotype of AHR was repeatedly shown in the present study.

The PAR receptor family (mainly PAR-1 and -2) has been intensively studied for its role in various types of inflammatory disorders (14), including allergic asthma. In contrast to EGFR, PARs are 7-transmembrane $G$ protein-coupled receptors (GPCRs) stimulated by serine proteases such as tryptase and thrombin. Although many studies have focused on the roles of PAR-2 and tryptase released from mast cells in allergic asthma (32), PAR-1 is also important in the pathogenesis of asthma. PAR-1 is widely expressed on leukocytes and airway cells in epithelium, smooth muscle, and blood vessels (33). The PAR-1-specific serine protease is thrombin, expression of which has been shown to be increased in asthmatic airways (34). A previous study demonstrated that $\alpha$-thrombin stimulates contraction of human bronchial rings by activation of PAR-1 (35). Furthermore, it has been demonstrated that thrombin-induced stimulation of PAR-1 promotes fibroblast 
Table III. Significant results of combination of SNPs in both genes of EGFR and PAR-1.

\begin{tabular}{|c|c|c|c|c|c|c|c|}
\hline \multirow[b]{2}{*}{ SNP loci } & & & \multicolumn{4}{|c|}{ Block } & \multirow[b]{2}{*}{ Cluster 1} \\
\hline & & & 1 & 2 & 3 & 4 & \\
\hline \multicolumn{8}{|l|}{ EGFR } \\
\hline rs 12668421 & 1 & $\mathrm{~A} / \mathrm{T}$ & & & & & \\
\hline rs4947488 & 2 & $\mathrm{~T} / \mathrm{A}$ & & & & & \\
\hline rs11766798 & 3 & $\mathrm{G} / \mathrm{A}$ & & & & & \\
\hline rs723527 & 4 & $\mathrm{G} / \mathrm{A}$ & & & & & \\
\hline rs9642564 & 5 & $\mathrm{~A} / \mathrm{G}$ & & & & & \\
\hline rs4947972 & 6 & $\mathrm{C} / \mathrm{G}$ & - & - & - & & \\
\hline rs12718945 & 7 & $\mathrm{G} / \mathrm{T}$ & $\bullet$ & - & - & & \\
\hline rs 13247687 & 8 & $\mathrm{~A} / \mathrm{G}$ & & & & & \\
\hline rs2072454 & 9 & $\mathrm{~T} / \mathrm{C}$ & - & & & & \\
\hline rs2227983 & 10 & $\mathrm{G} / \mathrm{A}$ & & - & & & \\
\hline rs1050171 & 11 & $\mathrm{G} / \mathrm{A}$ & & & & & \\
\hline rs2293347 & 12 & $\mathrm{~A} / \mathrm{G}$ & & & - & & $\bullet$ \\
\hline \multicolumn{8}{|l|}{ PAR-1 } \\
\hline rs27135 & 13 & $\mathrm{G} / \mathrm{A}$ & & & & & \\
\hline rs 2227750 & 14 & $\mathrm{G} / \mathrm{C}$ & & & & & \\
\hline rs37243 & 15 & $\mathrm{G} / \mathrm{A}$ & & & & $\bullet$ & \\
\hline rs37244 & 16 & $\mathrm{~T} / \mathrm{G}$ & & & & & \\
\hline rs253072 & 17 & $\mathrm{~A} / \mathrm{G}$ & & & & - & - \\
\hline rs 153311 & 18 & $\mathrm{C} / \mathrm{A}$ & & & & & \\
\hline rs5893 & 19 & $\mathrm{~A} / \mathrm{G}$ & & & & & \\
\hline P-value by Fisher's exact test ${ }^{\mathrm{a}}$ & & & 0.0183 & 0.00484 & 0.0226 & 0.00781 & 0.0426 \\
\hline Pearson's $\chi^{2}$ statistic value ${ }^{\mathrm{a}}$ & & & 13.6 & 16.8 & 13.1 & 11.9 & 8.17 \\
\hline
\end{tabular}

${ }^{\mathrm{a} I n} 2 \mathrm{x} k$ contingency table ( $k$, the number of haplotypes for cases and controls).

proliferation and collagen production (36). Accordingly, PAR-1 appears to be a new candidate factor for explaining the persistence of airway remodeling and the bronchoconstrictive response in asthmatic airways.

Recent accumulating evidence indicates that EGFR activation mediates PAR-1 mitogenic signaling through intracellular signaling crosstalk (15). For example, binding of the ligands to EGFR activates receptor and non-receptor tyrosine kinases which play a role in regulating small $\mathrm{G}$ proteins, such as $\mathrm{p} 21^{\text {ras }}$. The $\mathrm{p} 21^{\text {ras }}$ subsequently activates the MAP kinase pathway, resulting in consequent upregulation of transcription factors and immediate early genes that regulate growth. As for PAR-1, the receptor couples several $G$ proteins, which can activate various pathways that merge with the receptor tyrosine pathway at different levels. In particular, thrombin is known to activate non-receptor tyrosine kinase Src and Fyn. Collectively, it is likely that thrombin-PAR-1 systems and the EGFR pathway may synergistically lead to repair or remodeling of the airway epithelium. To the best of our knowledge, this is a novel genetic study which was designed to investigate an integrated effect of two different types of receptor genes which share an intracellular signaling interface system.

For this purpose, we newly proposed the concept of 'haplotype cluster' for genomic analysis. While the present study demonstrated that some haplotype blocks within each single gene (block-1, -2, -3 and -4) were associated with the presence of AHR, the findings also showed an integrated effect of haplotype cluster (cluster-1) over two genomic regions, providing novel insight into a role of gene interaction between these two receptors with signaling crosstalk in development of AHR. In addition, lower baseline $\mathrm{FEV}_{1}$ (\% predicted) was observed in subjects with AHR in comparison to those without AHR. This additional observation raises an intriguing suggestion that reduced airway caliber (albeit within normal range) might represent an occult repair process caused by the integrated effect of one haplotype cluster. Beyond the pair of EGFR and PAR-1, it is likely that the presence of AHR might partly arise from integrated effects of two or more genes in other various molecules which are synergistically involved in airway inflammatory and structural changes or airway smooth muscle contractibility per se. In the present study, we first termed such functionally-related genomic regions 'haplotype cluster'. This seems to be a novel and useful approach in future genetic studies to examine systematically such integrated effects of the numerous types of molecules in multifactorial disorders.

The limitation of the present study is the small number of subjects recruited. Despite such a small sample size, the present study approach is novel. We made sure that our study 
Table IV. Haplotype frequencies in EGFR and PAR-1 genes.

\begin{tabular}{|c|c|c|c|c|}
\hline Haplotype & & $\begin{array}{l}\text { Without AHR } \\
(n=111), \%\end{array}$ & $\begin{array}{l}\text { With AHR } \\
(n=54), \%\end{array}$ & P-value \\
\hline \multicolumn{5}{|c|}{ rs4947972, rs12718945 and rs2072454 ${ }^{a}$} \\
\hline $\mathrm{C}-\mathrm{G}-\mathrm{C}$ & 112 & 69.0 & 31.0 & 0.687 \\
\hline C-T-T & 121 & 73.4 & 26.6 & 0.351 \\
\hline \multirow[t]{2}{*}{ C-T-C } & 122 & 40.0 & 60.0 & 0.000983 \\
\hline & \multicolumn{4}{|c|}{ OR, 3.88 (1.89-7.98); RR, 3.32 (1.76-6.28) } \\
\hline G-G-C & 212 & 73.3 & 26.7 & 0.563 \\
\hline C-G-T & 111 & 66.7 & 33.3 & 1.000 \\
\hline G-G-T & 211 & 83.3 & 16.7 & 0.671 \\
\hline \multicolumn{5}{|c|}{ rs4947972, rs12718945 and rs2227983 ${ }^{b}$} \\
\hline C-G-A & 112 & 68.8 & 31.2 & 0.732 \\
\hline C-T-G & 121 & 75.0 & 25.0 & 0.230 \\
\hline C-G-G & 111 & 68.3 & $31.7 \%$ & 1.000 \\
\hline \multirow[t]{2}{*}{ C-T-A } & 122 & 37.1 & 62.9 & 0.000397 \\
\hline & \multicolumn{4}{|c|}{ OR, 4.11 (1.98-8.54); RR, 3.48 (1.82-6.64) } \\
\hline G-G-A & 212 & 70.8 & 29.2 & 0.830 \\
\hline G-G-G & 211 & 83.3 & 16.7 & 0.359 \\
\hline \multicolumn{5}{|c|}{ rs4947972, rs12718945 and rs2293347 } \\
\hline C-G-G & 112 & 69.8 & 30.2 & 0.607 \\
\hline C-G-A & 111 & 67.4 & 32.6 & 1.000 \\
\hline C-T-G & 122 & 70.1 & 29.9 & 0.629 \\
\hline G-G-A & 211 & 73.9 & 26.1 & 0.658 \\
\hline \multirow[t]{2}{*}{ C-T-A } & 121 & 31.8 & 68.2 & 0.000869 \\
\hline & \multicolumn{4}{|c|}{ OR, 5.81 (2.29-14.7); RR, 5.14 (2.16-12.2) } \\
\hline G-G-G & 212 & 76.9 & 23.1 & 0.566 \\
\hline \multicolumn{5}{|c|}{ rs37243 and rs $253072^{d}$} \\
\hline A-G & 22 & 68.9 & 31.1 & 0.678 \\
\hline A-A & 21 & 62.4 & 37.6 & 0.321 \\
\hline G-A & 11 & 75.8 & 24.2 & 0.151 \\
\hline \multirow[t]{2}{*}{ G-G } & 12 & 14.3 & 85.7 & 0.00619 \\
\hline & \multicolumn{4}{|c|}{ OR, 13.0 (1.54-109.4); RR, 12.3 (1.50-101.2) } \\
\hline \multicolumn{5}{|c|}{ rs2293347 and rs $253072^{\mathrm{e}}$} \\
\hline G-A & 21 & 73.8 & 26.2 & 0.147 \\
\hline A-G & 12 & 68.0 & 32.0 & 0.914 \\
\hline $\mathrm{G}-\mathrm{G}$ & 22 & 64.9 & 35.1 & 0.710 \\
\hline \multirow[t]{2}{*}{ A-A } & 11 & 48.6 & 51.4 & 0.0216 \\
\hline & \multicolumn{4}{|c|}{ OR, 2.42 (1.21-4.83); RR, 2.17 (1.19-3.96) } \\
\hline
\end{tabular}

By $2 \times 2$ contingency table. OR, odds ratio; RR, risk ratio. Airway hyperresponsiveness (AHR) was defined as $\mathrm{PC}_{20}<8.0 \mathrm{mg} / \mathrm{ml}$. Statistical power was ${ }^{\mathrm{a}} 0.928,{ }^{\mathrm{b}} 0.962,{ }^{\mathrm{c}} 0.922,{ }^{\mathrm{d}} 0.787$ and ${ }^{\mathrm{e}} 0.703$.

had adequate statistical power to detect the association of the haplotype with the phenotype. Considering the diversity of functionally-interrelated molecules in the pathogenesis of asthma, it seems crucial to accumulate evidence to determine the potential haplotype cluster over a large range of genomic regions as well as to recruit and collect as many as possible study participants.

In summary, the results of the present study suggest the importance of integrated genetic variations of EGFR and PAR-1 (haplotype cluster) which share common intracellular signaling pathways in the development of AHR even at the early stage of disease progression. Similar types of approaches as the present study using genomic analysis by identifying haplotype cluster in order to examine integrated effects of multiple genes will be needed in future studies.

\section{Acknowledgements}

The authors would like to thank Shimadzu Corporation, Kyoto, Japan for technical support and acquisition of SNP data and Komejun Co., Tokyo, Japan for advice with statistics. 


\section{References}

1. Sandford AJ and Paré PD: The genetics of asthma. The important questions. Am J Respir Crit Care Med 161: S202-S206, 2000.

2. Weiss ST, Raby BA and Rogers A: Asthma genetics and genomics. Curr Opin Genet Dev 19: 279-282, 2009.

3. Albuquerque RV, Hayden CM, Palmer LJ, Laing IA, Rye PJ, Gibson NA, Burton PR, Goldblatt J and Lesouëf PN: Association of polymorphisms within the tumour necrosis factor (TNF) genes and childhood asthma. Clin Exp Allergy 28: 578-584, 1998.

4. Burchard EG, Silverman EK, Rosenwasser LJ, Borish L, Yandava C, Pillari A, Weiss ST, Hasday J, Lilly CM, Ford JG and Drazen JM: Association between a sequence variant in the IL-4 gene promoter and FEV(1) in asthma. Am J Respir Crit Care Med 160: 919-922, 1999.

5. Van Eerdewegh P, Little RD, Dupuis J, Del Mastro RG, Falls K, Simon J, Torrey D, Pandit S, McKenny J, Braunschweiger K, et al: Association of the ADAM33 gene with asthma and bronchial hyperresponsiveness. Nature 418: 426-430, 2002.

6. Raby BA, Silverman EK, Kwiatkowski DJ, Lange C, Lazarus R and Weiss ST: ADAM33 polymorphisms and phenotype associations in childhood asthma. J Allergy Clin Immunol 113 1071-1078, 2004.

7. Hizawa N, Maeda Y, Konno S, Fukui Y, Takahashi D and Nishimura M: Genetic polymorphisms at FCER1B and PAI-1 and asthma susceptibility. Clin Exp Allergy 36: 872-876, 2006.

8. Tamer L, Calikoğlu M, Ates NA, Yildirim H, Ercan B, Saritas E, Unlü A and Atik U: Glutathione-S-transferase gene polymorphisms (GSTT1, GSTM1, GSTP1) as increased risk factors for asthma. Respirology 9: 493-498, 2004.

9. Moffatt MF, Kabesch M, Liang L, Dixon AL, Strachan D, Heath S, Depner M, von Berg A, Bufe A, Rietschel E, et al: Genetic variants regulating ORMDL 3 expression contribute to the risk of childhood asthma. Nature 448: 470-473, 2007.

10. Moffatt MF, Gut IG, Demenais F, Strachan DP, Bouzigon E, Heath S, von Mutius E, Farrall M, Lathrop M and Cookson WO A large-scale, consortium-based genomewide association study of asthma. N Engl J Med 363: 1211-1221, 2010.

11. Koppelman GH, Meyers DA, Howard TD, Zheng SL, Hawkins GA, Ampleford EJ, Xu J, Koning H, Bruinenberg M, Nolte IM, et al: Identification of $P C D H I$ as a novel susceptibility gene for bronchial hyperresponsiveness. Am J Respir Crit Care Med 180: 929-935, 2009.

12. Puddicombe SM, Polosa R, Richter A, Krishna MT, Howarth PH, Holgate ST and Davies DE: Involvement of the epidermal growth factor receptor in epithelial repair in asthma. FASEB J 14: 1362-1374, 2000.

13. Yoshikawa T, Kanazawa H, Tanaka J, Fujimoto S and Yamamoto T: Gene polymorphism of epidermal growth factor receptor and airway hyperresponsiveness in young allergic subjects without respiratory symptoms. Med Sci Monit 16: CR163-CR171, 2010.

14. Reed CE and Kita $\mathrm{H}$ : The role of protease activation of inflammation in allergic respiratory diseases. J Allergy Clin Immunol 114: 997-1008, 2004.

15. Dery O, Corvera CU, Steinhoff M and Bunnet NW: Proteinaseactivated receptors: novel mechanisms of signaling by serine proteases. Am J Physiol 274: C1429-C1452, 1998.

16. Daly MJ, Rioux JD, Schaffner SF, Hudson TJ and Lander ES: High-resolution haplotype structure in the human genome. Nature Genet 29: 229-232, 2001.

17. Crapo RO, Casaburi R, Coates AL, Enright PL, Hankinson JL, Irvin CG, MacIntyre NR, McKay RT, Wanger JS, Anderson SD, et al: Guidelines for methacholine and exercise challenge testing1999. Am J Respir Crit Care Med 161: 309-329, 2000.
18. World Medical Association Declaration of Helsinki: Ethical principles for medical research involving human subjects. Bull World Health Organ 79: 373-374, 2001.

19. Dempster AP, Laird NM and Rubin DB: Maximum likelihood from incomplete data via the EM algorithm. J Royal Stat Soc 39: 1-38, 1977 .

20. Hill WG: Estimation of linkage disequilibrium in randomly mating populations. Heredity 33: 229-239, 1974.

21. Excoffier L and Slatkin M: Maximum-likelihood estimation of molecular haplotype frequencies in diploid population. Mol Biol Evol 12: 921-927, 1995.

22. Wall JD and Pritchard JK: Haplotype blocks and linkage disequilibrium in the human genome. Nat Rev Genet 4: 587-597, 2003.

23. Shindo H, Chigira H, Tanaka J, Kamatani $\mathrm{N}$ and Inoue $\mathrm{M}$ : Grouping preprocess to accurately extend application of EM algorithm to haplotype inference. J Hum Genet 53: 747-756, 2008.

24. Hargreave FE, Ryan G, Thomson NC, O'Byrne PM, Latimer K, Juniper EF and Dolovich J: Bronchial responsiveness to histamine or methacholine in asthma: measurement and clinical significance. J Allergy Clin Immunol 68: 347-355, 1981.

25. Jansen DF, Timens W, Kraan J, Rijcken B and Postma DS: (A) symptomatic bronchial hyper-responsiveness and asthma. Respir Med 91: 121-134, 1997.

26. Hopp RJ, Townley RG, Biven RE, Bewtra AK and Nair NM: The presence of airway reactivity before the development of asthma. Am Rev Respir Dis 141: 2-8, 1990.

27. Brutsche MH, Downs SH, Schindler C, Gerbase MW, Schwartz J, Frey M, Russi EW, Ackermann-Liebrich U and Leuenberger P: Bronchial hyperresponsiveness and the development of asthma and COPD in asymptomatic individuals: SAPALDIA cohort study. Thorax 61: 671-677, 2006.

28. Boulet LP: Asymptomatic airway hyperresponsiveness: a curiosity or an opportunity to prevent asthma? Am J Respir Crit Care Med 167: 371-378, 2003

29. Laprise C, Laviolette M, Boutet M and Boulet LP: Asymptomatic airway hyperresponsiveness: relationships with airway inflammation and remodelling. Eur Respir J 14: 63-73, 1999.

30. Nomura N, Yoshikawa T, Kamoi H, Kanazawa H, Hirata K and Fujimoto S: Induced sputum analysis in asymptomatic young adults with bronchial hyperresponsiveness to methacholine. Respirology 12: 516-522, 2007.

31. Burgel PR and Nadel JA: Roles of epidermal growth factor receptor activation in epithelial cell repair and mucin production in airway epithelium. Thorax 59: 992-996, 2004.

32. Knight DA, Lim S, Scaffidi AK, Roche N, Chung KF, Stewart GA and Thompson PJ: Protease-activated receptors in human airways: upregulation of PAR-2 in respiratory epithelium from patients with asthma. J Allergy Clin Immunol 108: 797-803, 2001.

33. Kawabata A and Kawao N: Physiology and pathophysiology of proteinase-activated receptors (PARs): PARs in the respiratory system: cellular signaling and physiological/pathological roles. J Pharmacol Sci 97: 20-24, 2005.

34. Kanazawa $\mathrm{H}$ and Yoshikawa T: Upregulation of thrombin activity induced by vascular endothelial growth factor in asthmatic airways. Chest 132: 1169-1174, 2007.

35. Hauck RW, Schulz C, Schomig A,Hoffman RK and Panettieri Jr RA: Alpha-thrombin stimulates contraction of human bronchial rings by activation of protease-activating receptors. Am J Physiol 277: L22-L29, 1999.

36. Blanc-Brude OP, Archer F, Leoni P, Derian C, Bolsover S, Laurent GJ, and Chambers RC: Factor Xa stimulates fibroblast procollagen production, proliferation, and calcium signaling via PAR1 activation. Exp Cell Res 304: 16-27, 2005. 